\title{
Comprehensive photonics education model: the Albuquerque ladder
}

\section{Arthur Guenther, Leno Pedrotti}

Arthur H. Guenther, Leno Pedrotti, "Comprehensive photonics education model: the Albuquerque ladder," Proc. SPIE 9663, Eighth International Topical Meeting on Education and Training in Optics and Photonics, 96631S (6 October 2003); doi: 10.1117/12.2208475

SPIE Event: Eighth International Topical Meeting on Education and Training in Optics and Photonics, 2003, Tucson, Arizona, United States 


\title{
Comprehensive photonics education model - the Albuquerque ladder
}

\author{
Arthur H. Guenther \\ Center for High Technology Materials, University of New Mexico, 1313 Goddard Street SE, Albuquerque, New Mexico 87106 \\ telephone: (505) 272-7003; e-mail: $\underline{\text { agun @ chtm.unm.edu }}$ \\ Leno Pedrotti \\ Center for Occupational Research and Development, P.O. Box 21689, Waco, TX 76702-1689
}

\begin{abstract}
In direct response to the needs of the local optics and photonics sector, Albuquerque has established a comprehensive optics education program from middle school to post graduate. Individuals may enter and return to the workforce routinely as they ascend the degree chain. Quantitative details and progress will be presented as well as curricula.

(C)2003 Optical Society of America

OCIS codes: (000.2060) Education
\end{abstract}

Through an ideal blend of educational providers, local industry and civic leaders, unique career ladder in optics and photonics education is rapidly taking place in Albuquerque, New Mexico. This ladder is designed to provide focused education for students from high school through graduate school in support of a burgeoning need for skilled workers in optics and photonics. Depending on the various exit points along the ascending pathway. the educational delivery system is poised to provide a trained workforce that will include high school graduates at the entry-worker level, technicians with an associate of applied science degree, and optical scientists and engineers with preparation extending from baccalaureate to doctoral levels.

For some time now, the growing need for a skilled workforce in support optics/photonics industry has made manifest. A recent study by the National Academies of Science and Engineering, entitled "Harnessing Light) Optical Science and Engineering in the $21^{\text {st }}$ Century," points to an ongoing explosive growth in optics and photonics, predicting that optics and photonics will form the next major technology to drive our economy and improve our quality of life. The report points out that optics is pervasive, impacting the major fields of biomedicine, information technology. Defense and manufacturing, among others, leaving the reader with a clear impression that preparation of skilled workers in optics and photonics ought to be a national concern of high priority.

Eighth International Topical Meeting on Education and Training in Optics and Photonics,

edited by Barry L. Shoop, Grover Swartzlander Jr., Proc. of SPIE Vol. 9663, 96631S

(C) 2003 SPIE, OSA, ICO · doi: 10.1117/12.2208475

Proc. of SPIE Vol. 9663 96631S-1 


\section{Education Ladder for Careers in Optics Photonics}

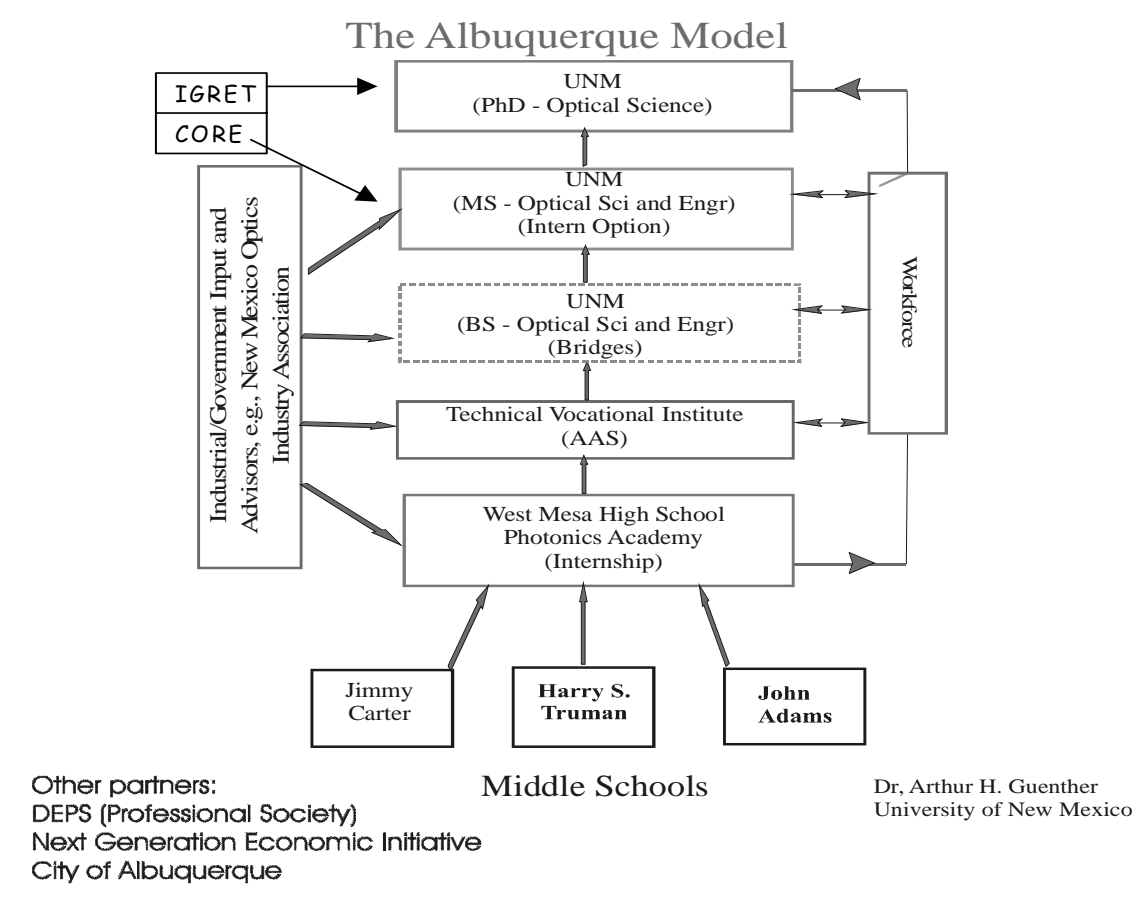

The career ladder in optics and photonics education-indicated here, begins with input from three middle schoolsfeeder schools that pipeline students into West Mesa High School. To make parent and students aware of exciting career opportunities in optics and photonics, and to fill the pipeline, counselors and teachers from WMHS visit feeder schools and provide career guidance through orientation sessions.

From the beginning. it was agreed that launching careers in optics and photonics would begin at the high school level, and that a Photonics Academy within the walls of the high school would be the way to go. The Photonics Academy would be the lynch pin that would hold the separate elements of the career ladder together. 